Vol. 8, Issue 5, May 2019

\title{
A Dual Band Elliptical Antenna for ISM and WIMAX Application
}

\author{
D.Stephy Angel ${ }^{1}$, M.Karthick ${ }^{2}$, J.Roselin Suganthi ${ }^{3}$ \\ Assistant Professor, Department of Electronics \& Communication, \\ K.Ramakrishnan College of Engineering Anna University, India ${ }^{1,2,3}$
}

\begin{abstract}
This paper proposes a dual band elliptical antenna for ISM and WIMAX applications. The antenna consists of elliptical patch connected to a line feed with a coplanar waveguide ground. This antenna operates at $2 \mathrm{GHz}$ and $3.5 \mathrm{GHz}$ with one port.This allows operation at ISM and WIMAX frequencies. The return loss $\mathrm{dB}(\mathrm{S}(1,1)=-16.8910 \mathrm{at} 2 \mathrm{GHz}$ and $\mathrm{dB}(\mathrm{S}(1,1)=-18.4981$ at $3.5 \mathrm{GHz}$ are obtained. The antenna is fabricated on $65 \mathrm{~mm} \times 120 \mathrm{~mm} \times 1.6 \mathrm{~mm}$ low cost FR4 epoxy substrate.The thickness of the substrate is $1.6 \mathrm{~mm}$. The antenna's radiation characteristics are verified and investigated by simulation results including radiation pattern,gain ,rEtotal ,return lossand 3D polar plot. The antenna design has been simulated by using Ansoft HFSS software.
\end{abstract}

Keyword: ISM; WIMAX; Coplanar Waveguide Ground

\section{INTRODUCTION}

Dual band antenna have many practical uses, especially for mobile devices. [1]These antennas operate on two frequencies simultaneously, depending on the capability of an antenna.The biggest advantage is to provide a strong, stable wireless connection. For this reason they are often used in devices such as cellular or dual band wireless access points. The frequencies used in this antenna are $2 \mathrm{GHz}$ and $3.5 \mathrm{GHz}$. Some dual band antennas can use both frequencies at once. The others can switch between the two frequencies depending upon which option provides a stronger connection. Dual band antennas are stable and are easy to connect.The advantages of elliptical shape is providing larger degrees of freedom and flexibility in the design. Circular polarization is achieved by exciting the elliptical patch rather than rectangular or circular ones. The elliptical antenna offers greater flexibility in the design. ISM means Industrial,Scientific and Medical applications known to many people due to its potential utilization in microwaveoven which operates at $2.45 \mathrm{GHz}$ uses microwaves to cook the food.Other applications of ISM band are induction heating,microwave heat treating, plastic softening,plastic welding processes.Microwaves is also used in medical applications for treating tumor cells.[5]WIMAX- WorldWideInterOperability for Microwave Access.It is a family of wireless broadband communications.[6]It is initially designed to operate over 30 to $40 \mathrm{Mbps}$. It is used to provide high speed data over wide area for mobile applications.[3]Coplanar waveguide is a planar transmission line. Itconsists of a single conducting metal strip printed onto a dielectric substrate along with a pair of return conductors. All of these conductors are on the same side of the dielectric substrate and hence it is called as coplanar. [11]CPW can be fabricate using PCB technology.

\section{DESIGN OF ELLIPTICAL PATCHANTENNA}

The radiating element is a elliptical patch designed by printing the patch on the FR4 Epoxy substrate having the dielectric constant of $\varepsilon_{\mathrm{r}}=4.4$ and a tangent lossof 0.02 .

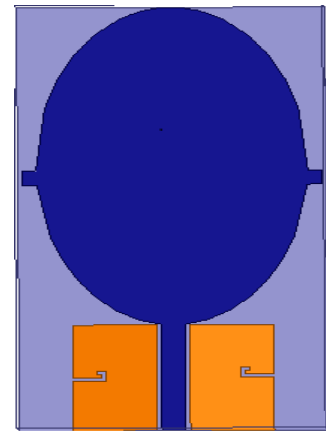

Figure 1 Geometry of Elliptical patch antenna 


\section{International Journal of Advanced Research in Computer and Communication Engineering}

Vol. 8, Issue 5, May 2019

The substrate height is taken as $1.6 \mathrm{~mm}$, a length of $65 \mathrm{~mm}$, a width of $120 \mathrm{~mm}$. The elliptical shape is chosen in order to provide the flexibility and larger degrees of freedom to the design. The radiating patch is fed by a strip line feed with a coplanar waveguide ground.[7]CPW ground has low dispersion and is used for broadband performance. The proposed elliptical patch is shown infigure 1.

Gain is a measure of antennas efficiency and its directional capabilities. It is measured in dB.The gain of the elliptical radiating patch is of $1.36 \mathrm{~dB}$ which is shown in the figure 2 .
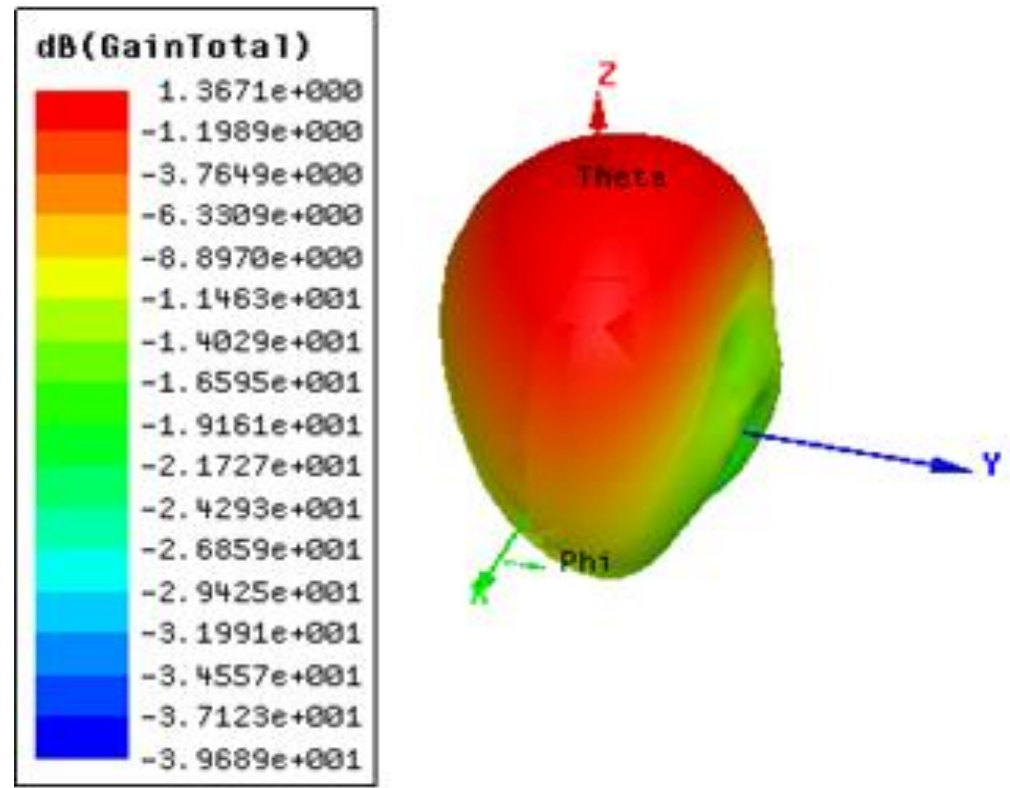

Figure 2 Gain of Elliptical patch antenna

Directivity of an antenna is defined as the ratio of the radiation intensity in a given direction from the antenna to the radiation intensity averaged over all directions. It is measured in dB.The directivity of elliptical radiating patch isof $2.04 \mathrm{~dB}$ which is shown in the figure 3 .
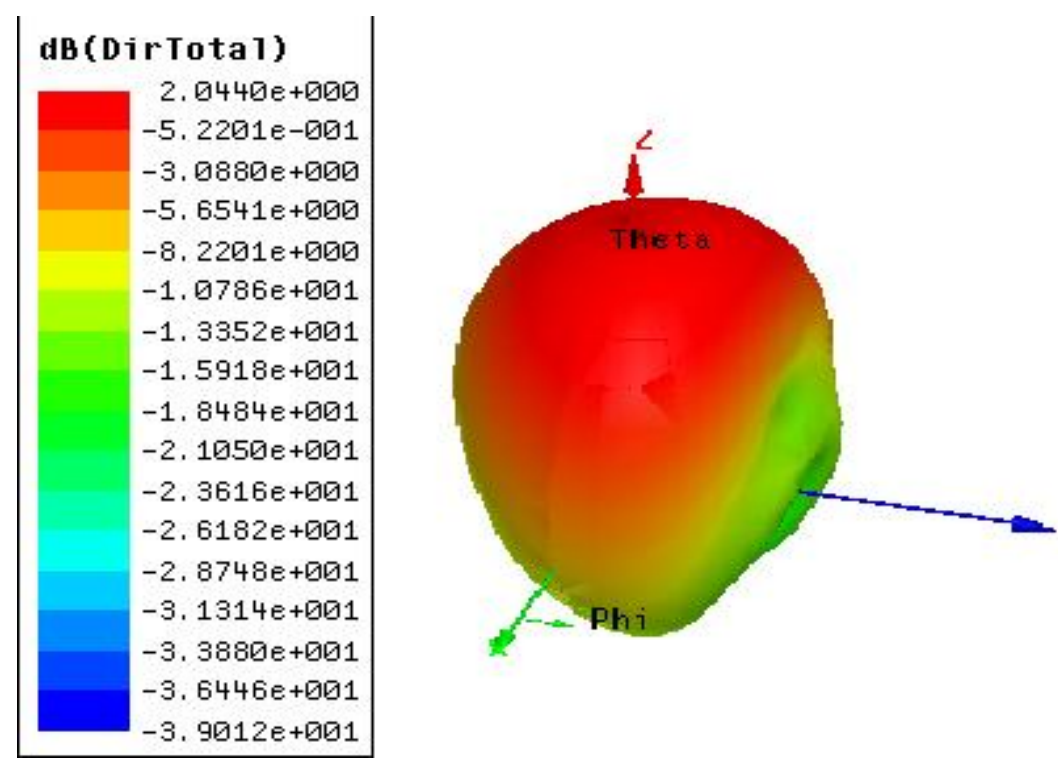

Figure 3 Directivity of Elliptical patch antenna

Return loss indicates the amount of reflection occurring at the same port and is the way of expressing the impedance mismatch. It is a logarithmicratiomeasuredindBthat compares the power reflected by the antenna to the power that is fed into the antenna from the transmission line. The return loss $\mathrm{dB}(\mathrm{S}(1,1)=-16.8910$ at $2 \mathrm{GHz}$ and $\mathrm{dB}(\mathrm{S}(1,1)=-18.4981$ at 3.5 $\mathrm{GHz}$ are obtained as shown in the figure 4. 
Vol. 8, Issue 5, May 2019

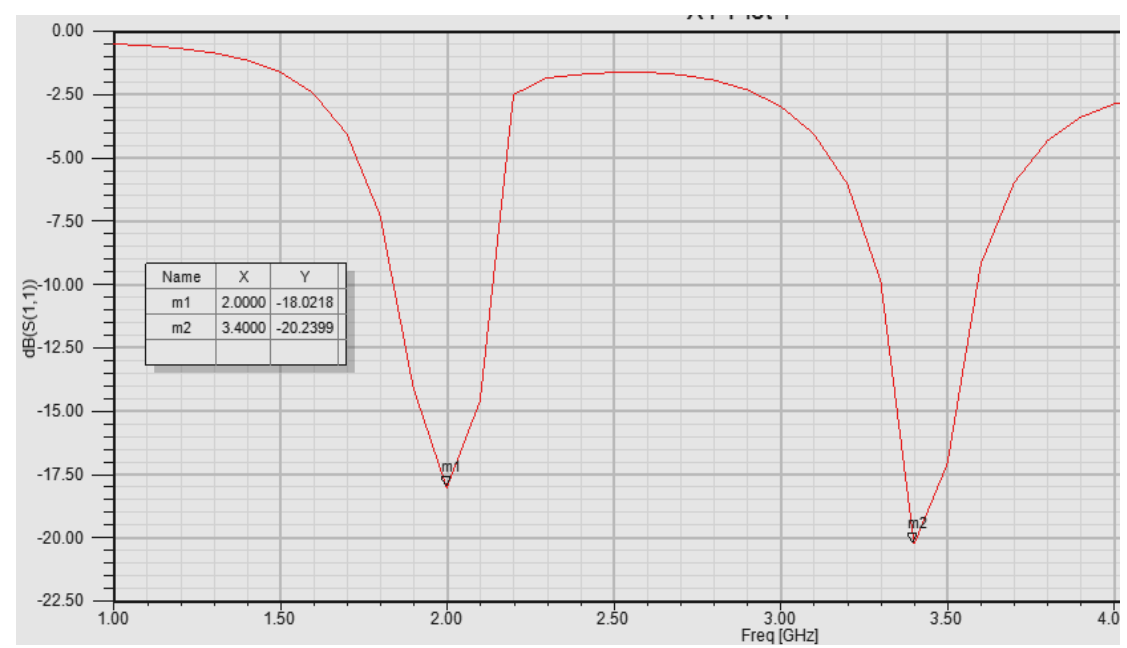

Figure 4 Return loss of Elliptical patch antenna with dual band

Radiation pattern is a graphical representation in $2 \mathrm{D}$ or $3 \mathrm{D}$ of the radiation of antenna as the function of direction. It is a plot of power radiated from an antenna per unit solid angle, which gives the intensity of radiation from the antenna. The $2 \mathrm{D}$ radiation pattern is shown in figure 5.In the proposed microstrip patch the fringing $\mathrm{E}-$ fields on the edge of the microstrip antenna add up in plane and produce the radiation of the microstrip patch antenna. It is observed that the $2 \mathrm{D}$ radiation pattern of elliptical patch antenna has one small back lobe and no side lobes as shown in the figure 5 .

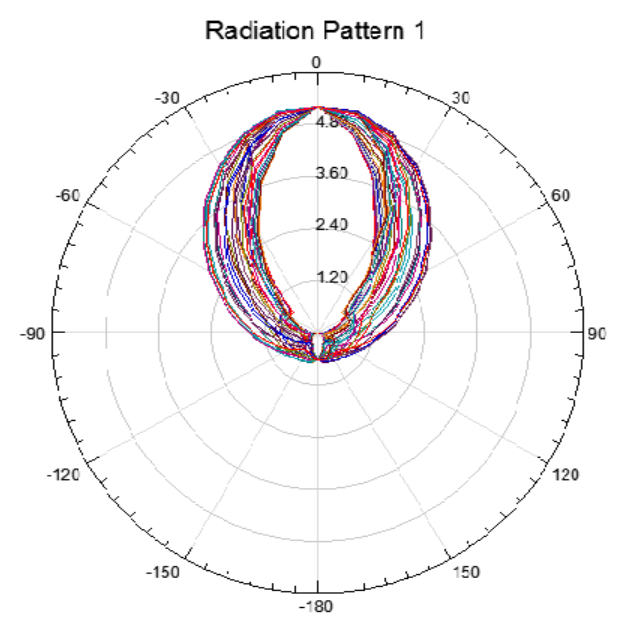

Figure 5 2D Radiation pattern of Elliptical patch antenna with dual band

The fabricated elliptical patch antenna is shown in the figure 6. It consists of the elliptical shaped metal patch feed by a strip line with a coplanar waveguide ground embedded on $65 \mathrm{~mm} \times 120 \mathrm{~mm} \times 1.6 \mathrm{~mm}$ FR-4 Epoxy dielectric substrate. The antenna's radiation characteristics are similar to the simulated results including radiation pattern, gain ,rEtotal ,return lossand 3D polar plot. The antenna design has been simulated by using Ansoft HFSS software.

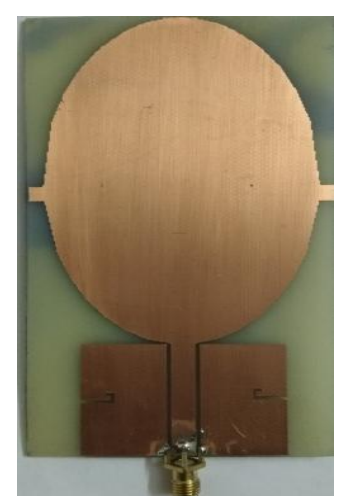

Figure 6 Fabricated Elliptical patch antenna 


\section{International Journal of Advanced Research in Computer and Communication Engineering}

Vol. 8, Issue 5, May 2019

III.

CONCLUSION

A Dual band elliptical antenna for ISM and WIMAX applications is proposed.In order to increase the gain and decrease the loss of the antenna elliptical patch is used.[12]The proposed design successfully operates over the solution frequency of about $2.4 \mathrm{GHz}$ and it radiates over the dual band frequencies such as $2 \mathrm{GHz}$ and $3.5 \mathrm{GHz}$. The return loss $\mathrm{dB}(\mathrm{S}(1,1)=-16.8910$ at $2 \mathrm{GHz}$ and $\mathrm{dB}(\mathrm{S}(1,1)=-18.4981$ at $3.5 \mathrm{GHz}$ are obtained. It has been experimentally verified by using Ansoft High Frequency Structure Simulator.In future this can be extended by using arrays and the performance can be analyzed with various substrates.

\section{REFERENCES}

[1]. Jandi, Y., F. Gharnati, and A. O. Said, "Design of a compact dual bands patch antenna for 5G applications," 2017 International Conference on Wireless Technologies, Embedded and Intelligent Systems (WITS), 1-4, IEEE, April 2017.

[2]. Anil Kumar, B Murugeshwari, S Raghavan, "Design of Substrate Integrated Waveguide Power Divider and Parameter optimization using Neural Network", IOSR Journal of Electronics and Communication Engineering (IOSR-JECE), Vol.13, issue.1, Ver.I (Jan-Feb. 2018), PP 37-43

[3]. R.Samson Daniel, "Design and Simulation of Multiband CPW feed Ring Shaped Antenna for Wireless Applications" International Journal of Engineering Sciences \& Research Technology, pp.549-553, 2014.

[4]. NagarajHanchinamani, Dr.C.R. Byrareddy, “A Survey of Microstrip Patch Antenna for MIMO” International Journal of Innovative Research in Computer and Communication Engineering,Vol-3, Issue-12, Dec 2015.

[5]. R Samson Daniel, R Pandeeswari, S Raghavan "Dual-band monopole antenna loaded with ELC metamaterial resonator for WiMAX and WLAN applications" Applied Physics A, vol.124, issue18,2018

[6]. N. ThamilSelvi, R. Pandeeswari, and P. N. ThiruvalarSelvan, An Inset-Fed Rectangular Microstrip Patch Antenna with Multiple Split Ring Resonator Loading for WLAN and RF-ID Applications, PIER C, vol.81, pp.41 - 52, 2018.

[7]. N. ThamilSelvi, P. N. ThiruvalarSelvan, S. P. K. Babu, R. Pandeeswari, and R. Samson Daniel, "A Broad-Side Coupled SRR Inspired CPW Fed Dual Band Antenna for WiMAX and Wave Applications", PIER C vol. 80, pp.221 -231, 2018.

[8]. S.Monisha, U.Surendar, “A Survey on Wearable Antenna for ISM Band Application”, IOSR Journal of Electronics and Communication Engineering, pp. 49-54, 2018.

[9]. S.Praveena, B.Murugeshwari, U.Surendar R. Kayalvizhi "A Review on Antenna Design for Millimeter Wave range", IOSR Journal of Electronics and Communication Engineering, pp. 01-06, 2018.

[10]. Gayathri R, Maheswari M, "Design And Fabrication Of Dual Band RFID Antenna Using Hybrid Coupler With CSRR", Pakistan Journal of Bio Technology, Vol.14(1), pp. 87-89, 2017.

[11]. VarikuntlaKrushnakanth, B.Murugeshwari\&SingaraveluRaghavan, "Design of a CPW Fed Substrate integrated waveguide using Frequency selective surface" $11^{\text {th }}$ International Radar symposium India( IRSI'17), Bangalore,India.

[12]. Muruganantham T, Surendar U, Balakumar"ADual Band Bandpass Filter With Sharp Passband Resonances Using Dual-Mode SIRs" International journal of microwave applications,volume 6, no.2,March-April 2017.

\section{BIOGRAPHIES}

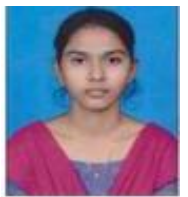

D.Stephy Angel workingas AssistantProfessor of Department of ECE inK.Ramakrishnan College of Engineering, Trichy,India. She completed her B.E and M.E(Communication Systems) in department of ECE at K.Ramakrishnan College of Engineering, Trichy,India. Her research interests are Antennas, Electromagnetic Fields, Transmission Lines, RF and Microwave Engineering.

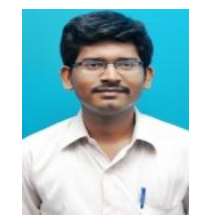

Mr.M.Karthick has obtained B.E (ECE) from Dr.G.U.Pope College of Engineering, M.Tech (Wireless Communication Systems), from PeriyarManiammai University, Thanjavur, Tamilnadu, India in the year 2010 and 2015 respectively. He has been serving as the faculty of Electronics and Communication Engineering for 9 years and he is currently working as Assistant Professor in the Department of ECE, K.Ramakrishnan College of Engineering, Trichy, India. He has published 5 papers in Reputed International journals and presented papers in more than 6 International Conferences. His areas of interest include Speech processing, Signal processing and Image processing.

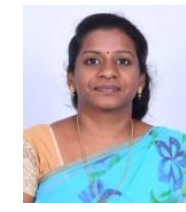

J.Roselin Suganthi working as Assistant Professor of Department of ECE in K.Ramakrishnan College of Engineering, Trichy,India. She completed her BE in department of ECE at Sudharsan Engineering College,Pudukkottai. She completed her M.E in department of Communication Systems at Mount Zion college of Engineering and technology,Pudukkottai. Her research interests are Wireless communication,NOMA,Signal processing. 